\title{
Joubert syndrome with ocular defect
}

INSERM

\section{Source}

INSERM. (1999). Orphanet: an online rare disease and orphan drug data base. Joubert syndrome with ocular defect. ORPHA:220493

Joubert syndrome with ocular defect is, along with pure JS, the most frequent subtype of Joubert syndrome and related disorders (JSRD, see these terms) characterized by the neurological features of JS associated with retinal dystrophy. 